\title{
PROJETO ARQUITETÔNICO DE EDIFÍCIO DE EDUCAÇÃO FUNDAMENTAL EM PRESIDENTE PRUDENTE/SP - ANÁLISE DE CASO
}

Claudia Jacqueline Sawada, Mariana Boa Sorte Faccin, Beatriz Minatti, Sibila Corral de Arêa Leão Honda, Maria Alessandra Bacaro Boscoli, Djanine Dolovet Martins

Universidade do Oeste Paulista - UNOESTE, Curso de Arquitetura e Urbanismo, Presidente Prudente, SP. E-mail: djanine@unoeste.br

\section{RESUMO}

Desde a Proclamação da República, as políticas educacionais têm sido utilizadas como veículo de marketing do governo instituído, por meio da execução de edificações que enaltecessem tais governos. Tais edifícios podem refletir as teorias pedagógicas em voga no período de seu projeto. Assim como, elementos da edificação também podem favorecer ou dificultar no processo de ensino, devido a aspectos de conforto. Nesse sentido, este artigo busca estudar um caso de edificação escolar de ensino fundamental I na cidade de Presidente Prudente-SP, focando nos aspectos projetuais da edificação, relacionando-os aos momentos históricos de sua execução. A metodologia seguida é qualitativa, e está baseada em aprofundamento teórico e conceitual, levantamentos físicos e projetuais, além de outros aspectos pertinentes.

Palavras - chave: Ensino fundamental, Edificação, Projeto de Arquitetura

\section{ARCHITECTURAL DESIGN OF ELEMENTARY SCHOOL IN PRESIDENTE PRUDENTE/SP - CASE STUDY}

\begin{abstract}
Since the Proclamation of the Republic, educational policies have been used as government marketing vehicle set through the execution of buildings that valorize those governments. These buildings can reflect the pedagogical theories in vogue during the period of your design. Besides, building elements can also promote or hinder the learning process due to considerations of comfort. In this sense, this paper seeks to study a case of school building of elementary school in Presidente Prudente-SP, focusing on projective aspects of the building, relating them to historical execution times. The methodology is qualitative, and is based on theoretical and conceptual depth, physical and projective surveys, as well as other relevant aspects.
\end{abstract}

Keywords: Elementary school, Construction, Architectural design 


\section{INTRODUÇÃO}

Após a Proclamação da República e no Governo de Getúlio Vargas (1930-1945), pode-se verificar que o processo de ampliação da rede escolar brasileira teve relação direta com o marketing desses novos governos.

Já no final do século XIX, o governo republicano brasileiro buscava demonstrar sua ação por meio da execução de escolas de arquitetura monumental. A ampliação do número de vagas e de escolas, a partir de então, tornou-se preocupação.

Ao mesmo tempo, os projetos e estilos arquitetônicos dessas edificações refletem as políticas públicas de cada período, mesmo que esses aspectos estejam relacionada ao objetivo de redução de custos.

A partir de 1979, devido à aprovação da Lei Federal 6.766, lei que trata de regras de parcelamento do solo urbano, verifica-se a obrigatoriedade de implantação de unidades escolares em todas as áreas urbanas, de forma espraiada.

Afinal, constata-se que os serviços e equipamentos públicos, e infraestrutura urbana são fundamentais, dentre os quais está a rede de ensino - infantil, fundamental e médio.

Atualmente, o ensino fundamental brasileiro, particularmente, está subdividido entre fundamental I e II, sendo que o I inclui educação para crianças entre 6 (incompletos) e 10 anos do 1 ㅇ. ao 5 ㅇ․ ano.

A Constituição Brasileira de 1988, atribui competência para prover escolas, vagas, estruturas, docentes para ensino fundamental nas cidades aos Estados e Municípios, embora no Estado de São Paulo, o ensino fundamental I foi municipalizado.

A partir disso, é importante verificar a adequação das edificações educacionais para os usos específicos, como equipamentos adequados para desenvolvimento social, cognitivo, educacional e motor das crianças; assim como a relação entre a tipologia da edificação e a oferta daqueles equipamentos com as teorias pedagógicas vigentes, como da possibilidade de correlacionar vários edifícios públicos com estilos arquitetônicos vigentes em determinados períodos.

Dessa forma, com vistas à área da Arquitetura e Urbanismo, o objetivo deste artigo é analisar edificação pública de ensino fundamental I em Presidente Prudente-SP, correlacionando seu projeto ao estilo arquitetônico vigente à época de construção, tendo como estudo de caso a E.M. Domingos Ferreira de Medeiros.

\section{METODOLOGIA}

A metodologia a ser utilizada nesta pesquisa será qualitativa. com aprofundamento da linha 
teórica e elaboração dos conceitos; com investigação prática por meio de levantamentos de documentos e de campo, mapeamentos e análises.

\section{ARQUITETURA ESCOLAR NO BRASIL}

O Brasil é, atualmente, um país predominantemente urbano. Durante o século XX, ocorreram fortes processos de migração e a imigração, inchando as cidades brasileiras, de forma rápida e sem infraestrutura e serviços públicos disponíveis. Estre estes, um dos mais importantes é a educação, cuja carência de vagas foi significativa.

A ideologia republicana brasileira, desde o final do século XIX, afirma que a educação seria fundamental, ou ordem propulsora para o progresso, sendo a escola o local de concentração da educação formal. E tinha como base a ideologia iluminista (SAVIANI et al, 2006).

Segundo Wolff (1992), a arquitetura escolar do final do século XIX nasceu buscando a propagação da propaganda da ação de governos por meio da educação democrática. E que a edificação escolar deveria divulgar a imagem de estabilidade, sendo facilmente percebidos e identificados.

Já na segunda metade da década de 1920, os projetos dos edifícios escolares sofreram alterações, visando-se a uma homogeneização da mensagem estética, cultural e ideológica, tendo sido proposto estilo neocolonial como padrão de arquitetura escolar (FARIA Fo. e VIDAL, 2000).

Mas, os custos de construção dessa tipologia de edifícios escolares eram bastante altos. Assim, na década de 1930, nos Estados do Rio de Janeiro e de São Paulo, configurava-se uma nova política voltada ao projeto arquitetônico de escolas públicas focando em edificações mais econômicas e simples, por meio da arquitetura funcionalista (FARIA Fo. e VIDAL, 2000). Até esse período, os Estados (antigas províncias) eram os responsáveis pelo ensino fundamental (escolas primárias).

No entanto, no governo de Getúlio Vargas (1930-1945) como Presidente da República, a educação foi considerada como questão nacional, cujo controle foi centralizado, tendo ocorrido regulamentação da educação brasileira em âmbito nacional (SAVIANI et al, 2006).

Nesse período, na arquitetura brasileira, muito se importava em relação à estilística de países europeus, como França e Itália, resultando no ecletismo no Brasil, estilo utilizado na maioria das edificações particulares e em muitos edifícios públicos (BRUAND, 2003, apud AZEVEDO, BASTOS, BLOWER, 2007).

A nova Constituição Brasileira foi sancionada em 1934, e a competência sobre as diretrizes da educação nacional ficou fixada como privativa da União. Em 1946, outra Constituição Federal foi 
sancionada, mantendo a União com a competência relativa à educação nacional.

A partir dos anos 1950, novamente com Getúlio Vargas como Presidente da República (1951-1954), a simplicidade e a economia na construção das escolas estavam cada vez mais disseminadas, alterando-se as concepções sobre os espaços escolares, otimizados e com redução dos custos.

Esses aspectos compactuavam com o repertório formal modernista, por meio de combinações de sólidos geométricos, linhas puras, sem ornamentos, sem simetria e com utilização de protetores solares (AZEVEDO, BASTOS, BLOWER, 2007).

Em dezembro de 1961, foi aprovada lei relativa às diretrizes - Lei de Diretrizes e Bases (LDB) da Educação Nacional, que sofreu grandes alterações em 1968 e 1971, sendo que em 1996 ela foi substituída pela atual LDB (SAVIANI et al, 2006).

Já em 1975, no Estado de São Paulo, devido ao aumento da demanda por vagas, o Governo Estadual buscou racionalizar o sistema projetivo, reduzindo os custos das obras e agilizando suas construções, que culminou na criação da Companhia de Construções Escolares do Estado de São Paulo - CONESP (AZEVEDO, BASTOS, BLOWER, 2007).

Em 1987, após o processo de redemocratização do país, o Governo Estadual paulista criou a Fundação para o Desenvolvimento da Educação (FDE), que visava a reunir todos os órgãos estaduais que tratavam de assuntos relativos à educação, seja em relação a aspectos físicos quanto pedagógicos (AZEVEDO, BASTOS, BLOWER, 2007).

Nesse mesmo ano, foi formada a Assembleia Nacional Constituinte, cuja Constituição foi sancionada no ano seguinte. Nessa nova carta magna, a competência sobre ensino fundamental voltou a ser dos Estados, mas compartilhada com os Municípios (CF, art.211, §§2‥e 3‥).

Em relação ao projeto da edificação de escola, Kowaltowski (2011) informa que quando ele é considerado de qualidade é porque surgiu devido à participação da comunidade com o processo educacional, não tendo foco somente no edifício. Mas, considerando a fase de projeto, os futuros usuários (docentes e sociedade) participam das propostas.

Afinal, o processo educacional apresenta grande importância na formação dos futuros cidadãos, e que projetos padrão não possibilitam a individualização das necessidades específicas de cada região ou faixa etária (AZEVEDO, 2002).

Considerando a cidade de Presidente Prudente, no interior do Estado de São Paulo, foco desta pesquisa, verifica-se a construção de edificações escolares desde sua criação legal no início da década de 1920. Uma delas é a E.M. Domingos Ferreira de Medeiros, estudo de caso desta pesquisa. 
Nesse rápido contexto histórico e arquitetônico, pode-se verificar como a realidade de análise dos projetos de arquitetura das unidades públicas de ensino fundamental é importante.

\section{ARQUITETURA CONTEMPORÂNEA NO BRASIL}

$\mathrm{Na}$ década de 1990, surge uma arquitetura progressiva em conjunto com ideais construtivos, como rigor das formas, além de uma busca pela tecnologia, porém, de forma mais amena do que os extremos da arquitetura moderna. A arquitetura Contemporânea utiliza de referências passadas em obras do futuro, com perspectivas mais horizontais, sem ter alguma barreira de criação, adaptando modelos passados (LUCCAS, 2008)

A aparência das obras da arquitetura contemporânea são confundidas com a arquitetura moderna, devido a revalorização do design moderno produzido ao longo dos anos, como móveis, acessórios, além de residências com abstração desde o projeto. No livro "Ainda Moderno? Arquitetura Brasileira Contemporânea", seu título já indaga se a produção atual brasileira ainda é moderna, pois ainda assim, leigos confundem o moderno com o contemporâneo (CAVALCANTI, LAGO. 2005)

Mies van der Rohe, Le Corbusier, Charlotte Perriand, ArneJacobsen, Achille Castiglione, Harry Bertoia e os Eames, entre muitos outros, são exemplos desta ligação entre o moderno e o contemporâneo.

De uma maneira geral, a arquitetura contemporânea evidencia traços do presente, do que se está vivendo naquele momento, com definições do passado, mas agregando na obra a tecnologia atual, tornando este projeto moderno e de acordo com o tempo em que está inserido. Isto não significa, entretanto, que toda arquitetura deva partir de referências explícitas para atingir sucesso.

O arquiteto contemporâneo Márcio Kogandisse, em entrevista para a Revista Projeto Design publicada em 2008, sobre a arquitetura contemporânea, informa que na Europa tem havido sobreposição de várias camadas numa só fachada, com três ou quatro fachadas em um único edifício. Mas que aqui no Brasil, não há supérfluos na arquitetura, considerando isso uma qualidade, ao mesmo tempo em que a sustentabilidade e o conforto do ambiente são considerados um caminho sem volta, com incorporação de práticas sustentáveis como a ventilação cruzada. 


\section{A ESCOLA COMO OBJETO DE ESTUDO}

A escola, em suas diferentes concretizações, é um produto de cada tempo, e suas formas construtivas são, além dos suportes da memória coletiva cultural, a expressão simbólica dos valores dominantes nas diferentes épocas (VIÑAO FRAGO; ESCOLANO, 1998, p. 47)

O objeto de estudo desta pesquisa foi a Escola Municipal de Ensino Fundamental Domingos Ferreira de Medeiros, que se localiza na Rua Arlindo Fantini, 91, Jardim Guanabara, em Presidente Prudente.

Faz-se notar que se trata de um projeto arquitetônico sem estilo definido, algo projetado apenas para atender o programa de necessidades. O pé direito é simples, os corredores e salas pouco iluminados e uma circulação entre os blocos um pouco confusa.

Com os conceitos de forma e cultura escolares, são postas em foco as práticas constitutivas de uma sociabilidade escolar e de um modo, também escolar, de transmissão cultural. Mas também são focalizados, a partir desses conceitos, os dispositivos que normatizam tais práticas: dispositivos de organização do tempo e do espaço escolar, dispositivos de normatização dos saberes a ensinar e das condutas a inculcar. (CARVALHO, 1998, p. 33)

As escolas públicas geralmente seguem um padrão construtivo onde a disposição de salas e pátios são muito semelhantes. Porém mesmo dentro do padrão pode-se oferecer melhorias, muitas vezes simples, às novas construções que farão grande diferença assim que se iniciar o funcionamento do edifício.

A escola de estudo está situada em um bairro mais carente da cidade, o Jardim Guanabara, conhecido como um dos bairros "além linha", próximo das áreas de maior criminalidade da cidade.

As condições das salas de aula não são as melhores, pois as lâmpadas não estão todas em perfeito funcionamento e as janelas não são suficientes para a claridade e ventilação necessárias. As salas de aula deveriam ser maiores ou conter menos alunos por turma para comportar a quantidade de alunos matriculados e os materiais utilizados em sala que não são levados para casa e ficam guardados nas próprias salas. Cada sala de aula é utilizada por duas turmas, uma no período da manhã e outra no período da tarde.

A escola conta com sistema de água filtrada, água encanada e tratamento de esgoto, além de energia elétrica, linha telefônica e internet banda larga, possui também quadra coberta, parque infantil e área verde. As crianças recebem também a merenda escolar.

O pátio onde se encontra o refeitório, possui também os banheiros masculino e feminino para uso das crianças, a cozinha, a despensa e o bebedouro com água filtrada e refrigerada. $\mathrm{O}$ 
balcão para servir as crianças, o bebedouro e as mesas e cadeiras são todos de menor altura, próprio para a altura das crianças.

Algo que chamou a atenção pela localização, é o refrigerador e o filtro da água para beber, que está na parte interna de um dos banheiros. Em alguns espaços foi possível encontrar vidros de janela pelo chão em local de total acesso das crianças.

A área verde que está a um nível mais alto e deveria ter proteção, tem apenas as estruturas metálicas, porém, sem fechamento, não fazendo a proteção. A escola também não tem interfone ou secretaria para acesso antes de entrar na escola, não ocasionando total segurança.

Muito há que precise ser corrigido quanto ao conforto do ambiente, à estruturação da edificação, aos equipamentos escolares disponíveis. A ausência de estilo arquitetônico pode ser aspecto identificador da falta de projeto de arquitetura adequado ao uso escolar.

\section{CONSIDERAÇÕES}

A partir de análise in loco, percebe-se a falta de cuidados em que a escola se encontra, e que melhorias precisam ser feitas para maior conforto dos alunos e funcionários. Restauro de pinturas e algumas mudanças em relação ao convívio escolar, como diminuir a quantidade de alunos em cada sala para melhor ventilação e conforto, ou criar novas salas para suportar grande quantidade de crianças. Isso melhoraria o desenvolvimento dos alunos e atrairia a vontade de estudar em uma escola organizada, colorida, limpa e mais segura.

\section{REFERÊNCIAS}

AZEVEDO, Giselle A.N. Arquitetura Escolar e Educação: um modelo conceitual de abordagem interacionista. (Tese de Doutorado) Rio de Janeiro: FAU-UFRJ. 2002. Disponível em: http://www.gae.fau.ufri.br/arq pdf/teses/arq esc gana.pdf. Acesso em 25.04.2015.

AZEVEDO, Giselle A.N.; BASTOS, Leopoldo E.G.; BLOWER, Hélide S. O moderno já passado - o passado no moderno. In: Anais do III Seminário Projetar. 2007.

BRASIL. Constituição Federal Brasileira. 1988.

CAVALCANTI, Lauro; LAGO, André Corrêa do. Ainda Moderno? Arquitetura Brasileira Contemporânea. Rio de Janeiro, Nova Fronteira, 2005.

FARIA Fo., Luciano Mendes de; VIDAL, Diana G. Os tempos e os espaços escolares no processo de institucionalização da escola primária no Brasil. In: Revista Brasileira de Educação. No. 14, PP.19-35. 2000. Disponível em: http://www.scielo.br/pdf/rbedu/n14/n14a03.pdf. Acesso em 06.02.2015.

GRUNOW, Evelise; Entrevista com Márcio Kogan. In: Revista Projeto Design; n.340, 2008. Disponível em: http://arcoweb.com.br/projetodesign/entrevista/marcio-kogan-nesta-entrevista- 
31-07-2008. Acesso em: 28 jun 2015.

KOWALTOWSKI, Doris C.C.K. arquitetura Escolar: o projeto do ambiente de ensino. São Paulo: Oficina de Textos, 2011.

LUCCAS, Luís Henrique H. Arquitetura contemporânea no Brasil: da crise dos anos setenta ao presente promissor. In: Arquitextos. 2008. Disponível em:

http://www.vitruvius.com.br/revistas/read/arquitextos/09.101/99. Acessado em 28 jun 2015. SAVIANI et al. O legado educacional do século XX no Brasil. 2a. Ed. Campinas: Autores Associados, 2006.

VIÑAO, Frago A.; ESCOLANO, A. Currículo, espaço e subjetividade: a arquitetura como programa. Rio de Janeiro: DP\&A, 1998.

WOLFF, Silvia. Espaço e educação. (Dissertação de Mestrado) São Paulo: FAU-USP. 1992. 